\title{
INTRODUCTION TO THE SPECIAL ISSUE ON POLICY
}

\author{
Bruce Chaloux \\ President, Sloan-C
}

The seeds for this JALN edition focusing on policy were planted more than four years ago. It evolved soon after Sloan-C began its annual survey and reflected concerns that policy-at the institutional, state, and federal levels - was lagging behind the growth curve in online learning. In short, the policy constructs at all levels, with some exceptions, targeted traditional on campus and classroom instruction and, to many in the ALN community, seemed at odds with the changing landscape of higher education.

In July, 2005, several of the authors met in Victoria, British Columbia at the Sloan-C Summer Research Workshop, where draft papers on several key policy issues were discussed. Post-meeting plans were to revise the series of papers on policy during the fall for publication in early 2006. The series of papers outlined and discussed several key policy challenges that were impeding, or could impede, the continued growth and development of online learning. The topics included the ongoing challenge of providing student services to remote learners and issues from tuition and pricing and financial aid to serving minority students and transnational programming.

All this changed in late August, 2005. To paraphrase Sondheim's award-winning musical, A <Not-so-> Funny Thing Happened on the Way to <this> Forum. Hurricane Katrina... and less than a month later, Hurricane Rita.

The powerful storms that ripped across the Gulf Coast of the United States, and the subsequent damage caused by levy breaks in the New Orleans, Louisiana area, changed dramatically the focus and attention of the Sloan-C community and, in some respects, all of higher education. To be sure, it changed the focus of this edition of JALN and delayed its release until the story, although still incomplete, could be better told.

Katrina caused the short-term or long-term shutdown of some 40 colleges and universities in the Gulf Coast region. Many institutions had to cease operations for a full academic term, some were out for several weeks, tens of thousands of students were displaced or, at best, had their academic activities interrupted. The storm spawned a response to the crisis from Sloan-C, and in reality the entire higher education community. In some respects, it was a coming of age for online learning, a turning point in the already significant growth and impact that Sloan-C's series of reports continues to underscore. Beyond the story of what was to be called "Sloan Semester" (a story told vividly in George Lorenzo's piece in this publication) and the overwhelming response to students impacted by the hurricanes, a new policy area emerged. Before the hurricanes, continuity of operations, or COOP, focused mainly on maintaining technical systems and operations. After the storms, and in the almost three years since those events, "academic COOP" has become part of the higher education lexicon.

So, the thrust of this publication changed and the emergence of academic COOP, emergency preparedness and how to utilize online learning to allow students to continue their educational pursuits in a crisis has taken center stage. It's still a work in progress, but we believe it has matured to the point where it's ready for JALN. 
As noted earlier, the first piece by George Lorenzo-The Sloan Semester-captures the efforts of Sloan-C, the Alfred P. Sloan Foundation, and hundreds of colleges and universities to make available, free to students, online courses. Beyond the students served, it demonstrates both the capacity and compassion of the broader community. It also underscores the need for far greater planning in advance of the next crisis, be it a storm, earthquake, bird flu outbreak, or some other event.

The next two pieces-Jon Link's Critical Event Preparedness and Response from the 2006 Sloan-C Summer Research Workshop and Don Spicer's Information Technology Services Support for Emergencies-provide a glimpse into the progress that has been made in thinking about emergency preparedness and planning. The community of interest has grown to the point where Sloan-C has established a web site focusing on the topic (visit http://academiccontinuity.org) for more information and resources.

The remaining pieces in this edition return to more "mainline” policy issues.

Bruce Chaloux addresses the challenges of financial assistance/aid for online learners in Overcoming the Financial Aid Barrier for E-learners. This is becoming a greater challenge as tuition and fee costs continue to rise and more students opt to pursue studies online.

Karen Paulson discusses the challenges of costing online learning in her Tuition/Pricing for Online Learning. She raises several critical questions which the higher education community must address if it is to maintain it egalitarian philosophy of learning opportunities for all.

In Student Learning and Student Services: Policy Issues Claudine SchWeber defines the continuing challenge and importance of student services, an area that many believe has not kept pace with the growth in the quality of online course instruction.

Janet Poley outlines the challenges of minority institutions in the adoption and use of online learning in Asynchronous Learning Networks: Policy Implications for Minority Serving Institutions and for Leaders Addressing Needs of Minority Learners.

Richard Skinner tackles the growing transnational marketplace and several policy considerations spurred on by technology and online learning in The Challenges of Transnational Online Learning. This was written, it should be noted, while he was president of Royal Roads University in Canada, which served students online from several countries.

Finally, Positioning Online Learning as a Strategic Asset in the Thinking of University Presidents and Chancellors by Sam Pete Smith, Sam Smith, Robert Samors and Frank Mayadas brings us full circle, back to institutional leadership and the importance of online learning as a strategy, and as a fulcrum for policy change, in colleges today.

To be sure, the policy issues raised in this issue are not the full agenda of topics that can and must be addressed. We expect to comment on more policy challenges in future editions of JALN. We hope this volume will inform and incite thinking about the importance of policy as online learning continues to flourish. Indeed, we must ensure that policy does not become a barrier or deterrent to the continued expansion of learning, in all forms and modalities.

My thanks to my colleagues and the Sloan-C and JALN editorial staff for their contributions and patience in getting this special edition of JALN completed. 